\title{
СТРУКТУРА И ПОДГОТОВКА КАДРОВ В СОВХОЗАХ ЗАПАДНОЙ СИБИРИ В 1928 - 1934 ГГ.
}

\section{THE STRUCTURE AND TRAINING OF PERSONNEL AT STATE FARMS IN WESTERN SIBERIA IN 1928-1934}

A. Plasulya

Summary: The article attempts to reconstruct the personnel structure of West Siberian state farms and the system for training and attracting personnel for state farms in the late 1920 s and early 1930 s. The dynamics of a quantitative change in the composition of state farm workers is shown. The author also examines staff turnover at state farms in Western Siberia, its causes and measures taken by the authorities to combat it.

Keywords: agrarian policy of the Soviet state, collectivization, state farms, Western Siberia, personnel structure, personnel training.
K адровая структура и подготовка кадров в совхозах Западной Сибири в конце 1920-х - середине 1930-х гг. - одна из недостаточно изученных страниц аграрной истории СССР. В советской историографии данная проблема не стала предметом специального исследования и рассматривалась кратко, в контексте общих вопросов совхозного строительства на общесоюзном материале $[1,2,3]$. В постсоветский период изучение развития государственного сектора аграрной экономики в СССР было фактически свернуто. Периодическое обращение к кадровой структуре совхозов имеет место в современных региональных исследованиях [4, 5], однако данный аспект деятельности совхозов пока еще мало изучен по материалам Западной Сибири. Выбор Западной Сибири в качестве территориальных рамок исследования объясняется тем, что регион являлся одним из ведущих районов СССР, производящих сельскохозяйственную продукцию. Целью настоящей статьи является конкретно-историческое исследование эволюции кадровой структуры, рассмотрение системы подготовки и привлечения трудовых кадров в западносибирские совхозы.

Смомента прихода квласти в 1917 г.большевики стремились к организации в деревне крупных коллективных хозяйств, а также совхозов («крупных социалистических экономий»). При этом совхозы признавались наиболее совершенным («последовательно-социалистическим») типом сельхозпредприятия. В Западной Сибири первые совхозы были созданы в 1918 г. Совхозное строительство в регионе возобновилось после восстановления в Сибири советской власти в 1920 - начале 1921 гг. В конце 1920-х гг. совхозное строительство в Западной Сибири
Плясуля Антон Александрович

соискатель, Институт истории СО РАН (Новосибирск) antonplyasulya1991@gmail.com

Аннотация: В статье предпринята попытка реконструировать кадровую структуру западносибирских совхозов и систему подготовки и привлечения кадров для совхозов в конце 1920-х - начале 1930-х гг. Показана динамика количественного изменения состава совхозных работников. Автор также исследует текучесть кадров в совхозах Западной Сибири, ее причины и предпринимаемые властью меры для борьбы с ней.

Ключевые слова: аграрная политика советского государства, коллективизация, совхозы, Западная Сибирь, кадровая структура, подготовка кадров.

активизировалось. Ставка была сделана на организацию крупных специализированных совхозов, которым отводилась важная роль в преобразовании аграрного сектора экономики.

Пополнение совхозов новой техникой, развитие новых отраслей производства, общая линия государства на интенсификацию сельскохозяйственного производства требовали особого внимания к проблеме подготовки и закрепления в совхозах квалифицированных кадров.

Рабочий аппарат совхозов в конце 1920-х гг. состоял из административно-технического персонала и рабочих различной квалификации. В штатном отношении рабочая сила делилась на: 1)постоянных рабочих; 2)сезонных работников; 3)поденных работников, нанимаемых на кратковременные работы; 4)подрядных или сдельных работников, нанимаемых на нерегулярные специальные работы - строительство ремонт и т. п. Основным источником рабочей силы для совхозов являлось окружающее крестьянское население. В зерновых совхозах обычно преобладал мужской труд, тогда как женщины и подростки находили себе применение в животноводческих $[6$, с. 83-84].

В большинстве совхозов 1928 - 1934 гг. наличествовал следующий основной кадровый состав работников: трактористы, комбайнеры, шоферы, помощники комбайнеров, механики, ветеринарные санитары, бригадиры-полеводы, бригадиры-животноводы, доярки (в основном, в молочно-мясных и масляных совхозах, с середины 1930-х гг. - в совхозах смешанной специали- 
зации) [7, л. 54].

В 1928 - 1932 гг. новым совхозам приходилось ежегодно набирать большое число сезонных и временных рабочих. Обращает на себя внимание, что в конце 1920-х гг. число постоянных рабочих значительно уступало общему числу сезонных и временных рабочих. Так, в 1929 г. в западносибирских совхозах работало 2,8 тыс. человек на постоянной основе, тогда как число временных и сезонных рабочих, вместе взятых, составляло 6,1 тыс. человек[8, с. 73]. Особенно много подсобной рабочей силы требовалось во время уборки урожая. Летом численность сезонных и временных обычно составляла не менее половины всех работающих в совхозах. По мере внедрения комбайна и превращения его в главную уборочную машину потребность совхозов в массовой рабочей силе сокращалась, однако росла потребность в механизаторских кадрах. Развитие животноводства и отказ от упрощенной агротехники также увеличили спрос на кадры массовых квалификаций и специалистов. И. Е. Зеленин отмечает, что наибольшее число руководящих работников, механизаторов и специалистов потребовалось совхозам в 1934 г. в связи с их укрупнением [3, с. 94].

С 1931 по 1934 гг. среднегодовое число постоянных рабочих в зерновых совхозах Западной Сибири выросло с 14407 до 23300 человек. При этом доля сезонных рабочих в это время была еще велика и составляла примерно 1/3 среднегодового числа рабочих (табл. 1).

Таблица 1

Численность рабочей силы в зерносовхозах Западной Сибири 1931 - 1934 гг. [9, с. 772-773]

\begin{tabular}{|l|c|c|c|c|}
\hline & 1931 г. & 1932 г. & 1933 г. & 1934 г. \\
\hline \multicolumn{5}{|c|}{ Постоянный рабочий персонал } \\
\hline & 5836 & 13483 & 18700 & 15900 \\
\hline Среднегодовое число рабочих \\
\hline В т. ч. постоянные & 8981 & 15300 & 11200 & 13358 \\
\hline В т. ч. сезонные & 5426 & 8000 & 9400 & 10594 \\
\hline
\end{tabular}

Среднегодовое количество постоянных рабочих в молочно-мясных совхозах Западной Сибири в 1933 г. составляло 65593 человека (из них 45982 - постоянные рабочие), в 1934 г. - 85783 человека (64931 - постоянные работники); в свиносовхозах - 9274 человека в 1933 г. и 12474 человека в 1934 г., в овцесовхозах - 7051 человек в 1933 г. и 9863 человека в 1934 г. Доля сезонных рабочих в животноводческих совхозах составляла, как правило, от $1 / 3$ до $1 / 2$ от общего среднегодового количества работников (табл. 2 - 4).
Таблица 2

Численность рабочей силы в молочно-мясных совхозах Западной Сибири в 1933 - 1934 гг. [9, с. 872-873]

\begin{tabular}{|l|c|c|}
\hline & 1933 г. & 1934 г. \\
\hline \multicolumn{3}{|c|}{ Постоянный рабочий персонал } \\
\hline \multicolumn{3}{|c|}{ Среднегодовое число рабочих } \\
\hline Всего & 58622 & 56452 \\
\hline В т. ч. постоянные & 41682 & 78586 \\
\hline в т. ч. сезонные & 16940 & 59856 \\
\hline
\end{tabular}

Таблица 3

Численность рабочей силы в свиносовхозах Западной Сибири в 1933 - 1934 гг. [9, с. 946]

\begin{tabular}{|l|c|c|}
\hline & 1933 г. & 1934 г. \\
\hline \multicolumn{3}{|c|}{ Постоянный рабочий персонал } \\
\hline \multicolumn{3}{|c|}{ Среднегодовое число рабочих } \\
\hline Всего & 10742 & 9718 \\
\hline В т. ч. постоянные & 6932 & 13466 \\
\hline В т. ч. сезонные & 3810 & 9846 \\
\hline
\end{tabular}

Таблица 4

Численность рабочей силы в овцесовхозах Западной Сибири в 1933 - 1934 гг. [9, с. 1012]

\begin{tabular}{|l|c|c|}
\hline & 1933 г. & 1934 г. \\
\hline \multicolumn{3}{|c|}{ Постоянный рабочий персонал } \\
\hline \multicolumn{3}{|c|}{ Среднегодовое число рабочих } \\
\hline Всего & 8023 & 5792 \\
\hline В т. ч. постоянные & 5082 & 9468 \\
\hline В т. ч. сезонные & 2941 & 5615 \\
\hline
\end{tabular}

К январю 1935 г. общая численность персонала западносибирских совхозов составляла 163,6 тыс. человек, из которых 146 тыс. человек были рабочими (из них 88 тыс. человек были постоянными рабочими), 4,2 тыс. человек - агрономы и инженерно-технический персонал, 7,1 тыс. человек - служащие [10, с. 260].

Для закрепления на сезонных работах отходников, Западно-Сибирский Крайисполком в мае 1931 г. постановил на время летних работ предоставлять сельскохозяйственный инвентарь и тягловую силу в первую очередь сезонным работникам [11].

Значительно укреплялись механизаторские кадры совхозов. Вот как, например, выглядела динамика подготовки трактористов в зерносовхозах Западно-Сибирского края в 1929 - 1931 гг.: в 1929 г. было подготовлено 600 трактористов, в 1930 г. - 3414, в 1931 г. - 8707 [12, с. 
389]. В 1932 - 1933 гг. совхозы Западно-Сибирского края подготовили 14 тыс. трактористов, 732 бригадира тракторных бригад, 2 тыс. комбайнеров, 692 шофера, 636 техников [12, с. 389-390].

Как руководящие кадры, так и специалисты в совхозах поступали, как правило, через государственную сеть сельскохозяйственных вузов и техникумов [3, с. 94]. Во время второй пятилетки государство приняло ряд мер по улучшению их работы.

25 февраля 1934 г. ЦК ВКП(б) принял постановление «О сельскохозяйственных техникумах СССР», в котором было указано на недопустимость чрезмерно дробной номенклатуры техникумов, которые готовили в среднем специалистов по 60 специальностям, и установил перечень специальностей для специалистов среднего звена [3, с. 94-95]. В соответствии с этим постановлением Наркомат совхозов СССР в марте 1934 г. определил, что техникумы Наркомата должны готовить специалистов семи профилей: младших агрономов со специализацией на последних курсах по зерну, семеноводству и луговодству; младших зоотехников со специализацией по видам скота: механиков со специализацией по тракторам, комбайнам и ремонту; гидротехников-механизаторов; техников-строителей; механиков по переработке сельскохозяйственных продуктов; помощников ветеринаров [3, с. 95].

Кадры массовых производственных квалификаций готовили в основном внутри совхозов [3, с. 96]. В 1928 1932 гг. стационарных форм подготовки практически не было, действовала система краткосрочных курсов [3, с. 96]. Программа подготовки механизаторов, рассчитанная на 2 - 3 месяца, на практике могла сокращаться до 2 - 4 недель, поэтому качество такой подготовки было весьма низким. Требовались изменения в системе образования [3, с. 96]. В результате с 1933 г. при совхозах создавались постоянные школы для подготовки механизаторов при трестах со сроком обучения в них от 4 месяцев до года [3, с. 97]. Аналогичные постоянные школы создавались также для подготовки механиков, бригадиров тракторных бригад, трактористов, комбайнеров и шоферов, животноводов.

В Сибири наряду с подготовкой новых совхозных кадров через курсы массовых профессий и техникумы немалое значение придавалось подготовке новых кадров заочным путем. В начале 1930-х гг. Западно-Сибирское краевое земельное управление разворачивало сеть заочных секторов при сельскохозяйственных вузах и техникумах для подготовки кадров высшей, средней, низшей и массовой квалификаций. Среди прочих на учебу принимали работников совхозов, в первую очередь - ударников труда. При совхозах организовывались отборочные комиссии для выбора будущих обучающихся [13].
Высокая степень текучести кадров в совхозах Сибири была одной из самых значительных проблем. Так, в 1932 г. по зерносовхозам Западно-Сибирского края убыло 2264 тракториста, 1068 комбайнеров, 215 бригадиров, 368 шоферов [12, с. 398]. Из подготовленных в 1931 1932 гг. 13520 трактористов и 3158 комбайнеров к 1933 г. осталось 3665 трактористов (27\%) и 1484 комбайнера (47 \%) [12, с. 398]. Иначе говоря, совхозы испытывали острый недостаток квалифицированной рабочей силы. В 1931 - 1932 гг. в совхозе № 48 «Маслотреста» текучесть рабочей силы составляла примерно 50 \% [14, л. 14]. По результатам проверки состояния Ново-Алексеевского овцесовхоза, последнему не хватало инспектора по брынзоделию, механизатора, 2 бригадиров-трактористов, 14 трактористов [15, л. 5]. Одним из наиболее распространенных проявлений текучести кадров состояло в том, что рабочие совхозов переходили на работу в промышленные предприятия. Так, летом 1933 г. несколько слесарей и токарей перешли работать из Прокопьевского совхоза в Прокопьевский рудник по причине того, что в руднике для них зарплата была в 1,5 - 2 раза выше, чем в совхозах [16, л. 3]. Согласно секретной спецсводке ОГПУ «О подготовке к уборке урожая хлебов», в июне 1931 г. совхозам «Скотовода» требовалось 58190 человек, фактически работало 11458, совхозы «Овцевода» нуждались в 8 тыс. человек, фактически в них имелось 1,6 тыс. работников [17, с. 436].

Одной из причин увольнения и перехода рабочих в другой совхоз являлась задержка заработной платы. В связи с этим ряд совхозов испытывал перманентную нехватку квалифицированных специалистов. Известно, например, как данную проблему пытались решить Новосибирский и Омский «Зернотресты»: они присылали в совхозы своих специалистов в командировочном порядке. Однако к 1934 г. выяснилось, что значительная часть зерновых совхозов слишком часто запрашивает к себе специалистов треста и нередко даже злоупотребляла вызовами $[18$, л. 10]. В связи с этим 18 июля 1934 г. Новосибирский «Зернотрест» издал приказ, который строго регламентировал порядок командировок из треста в совхоз. Командировка по инициативе треста должна была проходить за счет утвержденного лимита треста, командировка специалиста по вызову директора совхоза для временной работы в зерносовхозе оплачивалась за счет данного совхоза $[18$, л. 10].

Нередко сотрудники «Зернотреста» просили разрешения перевестись на работу в совхоз, обосновывая это невозможностью ходить на работу в трест за несколько километров [19, л. 220-222].

Другой причиной текучести кадров были неудовлетворительные жилищно-бытовые условия для рабочих в отдельных совхозах. Осенью 1932 г. Наркомат зерновых и животноводческих совхозов СССР, которому совхозы 
переданы в непосредственное управление 1 октября 1932 г., признал неудовлетворительным бытовое обслуживание совхозных работников, особенно по части их обеспечения собственным хозяйством. 29 октября 1932 г. Коллегия Наркомата совхозов постановила провести следующие мероприятия:

«...1. Не только не препятствовать работникам зерновых и животноводческих совхозов иметь в личном пользовании коров, мелкий скот и птицу, но и оказывать всяческое содействие в разведении и содержании их (отведение пастбищ, сенокосов, предоставление орудий для обработки, предоставление погребов для засолки).

2. Немедленно отвести специальные приусадебные земельные участки, в которых предоставить возможность рабочим самим застраиваться и около застроек отвести огородную землю.

3. В мастерских совхозов в свободное от ремонта сельскохозяйственных машин и орудий время организовать изготовление предметов широкого потребления для работников совхозов (мебель, кухонную посуду и др. предметы).

4. Обязать Директоров совхозов немедленно обсудить, совместно с партийными и профессиональными организациями совхозов, дополнительные занятия, могущие улучшить бытовое положение работников совхозов и обсудить на общих собраниях работников совхозов специальный доклад о мероприятиях, которые будут проведены Дирекцией совхозов...» [20, л. 17]

В начале 1930-х гг. центральное управление «Союзскотоводобъединения» выражало недовольство невнимательным отношением по части материально-бытового обслуживания ветеринарных врачей, зоотехников, агрономов, инженеров, бухгалтеров, счетоводов со стороны директоров совхозов [21, л. 3-4]. По некоторым совхозам системы «Овцевод» в 1933 г. также констатировался факт неудовлетворительных жилищно-бытовых условий для рабочих. Например, подобное наблюдала комиссия Западно-Сибирского Крайкома ВКП(б) в Родинском овцесовхозе: вместо положенных работникам обустроенной комнаты их поместили в барак $[22$, л. 1].

Чтобы бороться с текучкой кадров, сибирские власти периодически предпринимали меры. 10 июня 1933 г. Наркомат совхозов СССР признал правильным решение западносибирских партийных организаций о предоставлении кредитов на индивидуальное строительство рабочим совхозов в сумме до 450 рублей на двор. Кредитование индивидуального строительства шло по линии Соцзембанка, из краевых ресурсов. В случае окончания строительства к 1 сентября 1933 г. Наркомат постановил увеличить финансирование на жилищное строительство для совхозных рабочих по Западной Сибири на 2 млн. рублей [23, л. 101 об]. 6 декабря 1933 г. на VI пленуме Западно-Сибирского краевого комитета ВКП(б) было принято постановление, согласно которому для закрепления рабочих кадров в совхозах в 1934 г. директоров совхозов обязали добиться такого положения, чтобы ведущие кадры и ударники имели продуктивный скот, собственный огород и закрепленную за ним жилплощадь. Также было предписано оказать максимальное содействие работникам совхозов в развитии мелкого приусадебного животноводства (овцы, свиньи, птица, кролики, пчелы) [24, л. 75-76].

В Сибири в начале 1930-х отмечалась неудовлетворительная подготовка кадров. Например, в 1932 г. партийными органами было выяснено, что в «Зернотресте» и Трактороцентре не вели учет мероприятий по подготовке кадров, а райкомы не проверяли работу совхозов в этом деле. Комплекс мер, принятых по этому вопросу, был достаточно стандартный: «1)За слабую подготовку работы, за неудовлетворительное руководство подготовкой кадров по зерносовхозам снять с работы зав. отд. кадров Зернотреста т. Саяпина и объявить ему выговор. Зав. кадрами КрайЗУ т. Третьяку за неудовлетворительное руководство подготовкой кадров к весеннему севу, отсутствие программно-методического руководства и контроля за ходом подготовки - поставить на вид. 2)Указать райкомам: Баевскому, Баелакскому (Чарышскому), Томскому, Татарскому, Барабинскому, Коченевскому за недопустимо слабое развертывание курсовых мероприятий, которое грозит полным срывом подготовки кадров к весеннему севу <...> 4)Обязать КрайзУ, Трактороцентр, Зернотрест и Крайколхозсоюз к 1 марта 1932 г. учесть полностью по всем совхозам, МТС, курсовым базам, количество развернутых курсов и число подготовляемых на них кадров по квалификациям. <...> 5)Обязать директоров МТС, Зерносовхозов и председателей райколхозсоюзов к 10/III-32 г. произвести полный учет колхозников и рабочих совхозов, прошедших специальную курсовую подготовку бригадиров: полеводов, механиков, трактористов-рулевых, закрепить их на сельскохозяйственных работах и прекратить массовое разбазаривание этих квалификаций <..> 6)Обязать директоров совхозов, MTC, фр. РИКов и райколхозсоюзов обеспечить качественную сторону подготовки кадров, для чего особо должно быть обращено внимание на подбор курсантов (в первую очередь, ударников), обслуживание преподавательским и агрономическим персоналом, обеспечение производственной практики, учебными пособиями и учебниками и строгое соблюдение сроков подготовки. 7)В связи с острым недостатком агрономического персонала в МТС, поручить Крайколхозсоюзу и Трактороцентру провести выдвижение колхозников и полеводов, имеющих практический опыт, на работу агротехниками в МТС. 8)горкомам и райкомам - чутко относиться к специалистам сельского хозяйства и принимать конкрет- 
ные меры для улучшения материально-бытовых условий специалистов. Райкомы, горкомы, парткомы, рабочкомы и директора совхозов должны обеспечить нормальные материальные бытовые условия для работающих в совхозах. 9)Предложить райкомам и горкомам партии срочно провести проверку работы по подготовке кадров к весенней посевной кампании для МТС, совхозов $<\ldots>$ обратив особое внимание на качество подготовки и принять решительные меры к улучшению их работы, поставив в центре внимания наряду с другой оперативно-хозяйственной работой» [25, л. 182-184].

В 1933 г. не были в достаточной степени укомплектованы курсы трактористов по Чарышскому, Алтайскому и Крутоярскому зерносовхозам [26, л. 49].

В плане подготовки кадров Западно-Сибирским крайкомом ВКП(б) прежде всего было принято постановление «Об организации Краевой школы по подготовке трактористов-механиков и организации школы подготовки трактористов-бригадиров» от 25 августа 1933 г. Это была постоянно действующая школа по подготовке трактористов-механизаторов для МТС и совхозов, расположенная в Колывани. Командируемые на учебу в эту школу отбирались директорами и политотделами МТС и совхозов [27, л. 92]. На VI пленуме Запсибкрайкома ВКП(б) было принято решение вести систематическую работу с бригадирами по вооружению их агротехническими зна- ниями и развернуть в совхозах подготовку кадров массовых квалификаций (бригадиры, доярки, сеяльщики и т. д.) $[28$, л. 38]. Вообще, органы власти придавали важное значение подготовке кадров как средству укрепления совхозов и сохранения кадровой стабильности.

В середине 1930-х гг. увеличилось качество подготовки квалифицированных кадров для совхозов. К январю 1935 г. для совхозов Западно-Сибирского края было подготовлено около 32 тыс. трактористов, 4,5 тыс. комбайнеров, 2 тыс. бригадиров, 11,4 тыс. рабочих на различные сельскохозяйственные машины, 14,2 тыс. животноводов $[29$, л. 9].

Несмотря на определенные трудности и недостатки в Западной Сибири в середине 1930-х гг. наметилось значительное улучшение в вопросах закрепления кадров и их подготовки. Этому способствовали не только конкретные меры власти по поводу работы с кадрами в совхозах, но и ряд объективных процессов: в середине 1930-х гг. шло разукрупнение совхозов, прекратилось образование новых, преодолена чрезмерная специализация, совершенствовалась степень механизированности, осуществлялся переход на сдельную систему оплаты труда, достигнуто улучшение финансового состояния работников совхозов. Все это создавало предпосылки для уменьшения текучести и закрепления постоянных кадров в совхозах.

ЛИТЕРАТУРА

1. Богденко М.Л., Зеленин И.Е. Совхозы СССР. Краткий исторический очерк (1917-1975). М.: Политиздат, 1976. 279 с.

2. Зеленин И.Е. Зерновые совхозы СССР. 1933-1941. М.: Наука, 1966. 246 с.

3. Зеленин И.Е. Совхозы СССР в годы довоенных пятилеток. 1928-1941. М.: Наука, 1982. 235 с.

4. Трофимова А.И. Механизм совхозообразования в начале 1930-х гг. (на материалах Европейского Севера РСФСР) // Исторические, философские, политические и юридические науки, культурология и искусствоведение. Вопросы теории и практики. 2013. № 7 (33). Часть 2. С. 167-169; Она же. Правовое положение категорий совхозного социума России в 1930-1950-х гг. (по материалам Европейского Севера РСФСР) // Актуальные проблемы российского права. 2014. № 9 (46). С. 1833-1842; Она же. Процесс экономической модернизации в совхозах России в 1930-1950-х гг. (на материалах Европейского Севера РСФСР) // Историческая и социально-образовательная мысль. 2013. № 4 (20). С. 42-45; Она же. Совхозы Европейского Севера РСФСР в 1930 1950-е гг. автореф. дис... канд. ист. наук. Вологда, 2014.

5. Казакова К.А. Развитие сельскохозяйственного производства в лагерях ГУЛАГа на территории Коми АССР в 1930 - 1950-е гг. // Вестник Поморского университета. Серия: гуманитарные и социальные науки. 2009. № 2. С. 5 - 9; Она же. Сельхозы Воркутлага в 1930-1950-е годы // Известия РГПУ им. А.И. Герцена. 2009. № 90. С. 48 - 53.

6. Галевиус Ф.К. Проблема труда в крупном хозяйстве СССР // Аграрные проблемы. Кн. 5 - 6. М.: Международный аграрный институт, 1928. С. 82 - 108.

7. Российский государственный архив экономики (далее - РГАЭ). Ф. 7803. Оп. 2. Д. 1300.

8. Труд в СССР. Справочник 1926 - 1930 гг. М.: гос. план.-хоз. изд-во Планхозгиз, 1930. 104 с.

9. Сельское хозяйство СССР. Ежегодник. 1935. М.: Государственное издательство колхозной и совхозной литературы «Сельхозгиз», 1936.1465 с.

10. Труд в СССР. Статистический справочник. М.: ЦУНХУ Госплана СССР и В/о Союзоргучет, 1936. 386 с.

11. 06 оказании помощи при уборке семьям отходников // Сборник постановлений и распоряжений президиума Западно-Сибирского Крайисполкома, его отделов и управлении. 1931. № 10. С. 131.

12. Гущин Н.Я. Сибирская деревня на пути к социализму: социально-экономическое развитие сибирской деревни в годы социалистической реконструкции народного хозяйства. 1926-1937 гг. Новосибирск: Наука, Сибирское отделение, 1973. 516 с.

13. О заочном с.-х. образовании // Сборник постановлений и распоряжений президиума Западно-Сибирского Крайисполкома, его отделов и управлении. 1931. № 14. С. 193. 
14. Государственный архив Новосибирской области (далее - ГАНО). Ф. П-3. Оп. 2. Д. 152.

15. ГАНО. Ф. Р-359. ОП. 1.Д. 82.

16. ГАНО.Ф.П-З. ОП. 1.Д. 541.

17. Голод в СССР: В З т. Т. 1. 1929 - июль 1932. Кн. 1. М.: МФД, 2011.656 с.

18. РГАЭ. Ф. 7803. ОП. 1. Д. 184.

19. ГАНО.Ф. Р-366. ОП. 2. Д. 18.

20. ГАНО. Ф. Р-366. Оп. 1. Д. 36.

21. ГАНО.Ф.Р-285. Оп. 1.Д. 192.

22. ГАНО.Ф. Р-359. ОП. 1. Д. 83.

23. ГАНО.Ф.Р-311.0п. 1.Д.7.

24. ГАНО.Ф. П-З. ОП. 2. Д. 419.

25. ГАНО. Ф. П-З ОП. 2. Д. 299.

26. ГАНО.Ф.П-З. ОП. 2. Д. 435.

27. ГАНО.Ф.П-З. ОП. 2. Д. 431.

28. ГАНО.Ф. П-З. ОП. 2. Д. 571.

29. ГАНО.Ф. П-З. ОП. 2. Д. 569.

(с) Плясуля Антон Александрович (antonplyasulya1991@gmail.com).

Журнал «Современная наука: актуальные проблемы теории и практики»

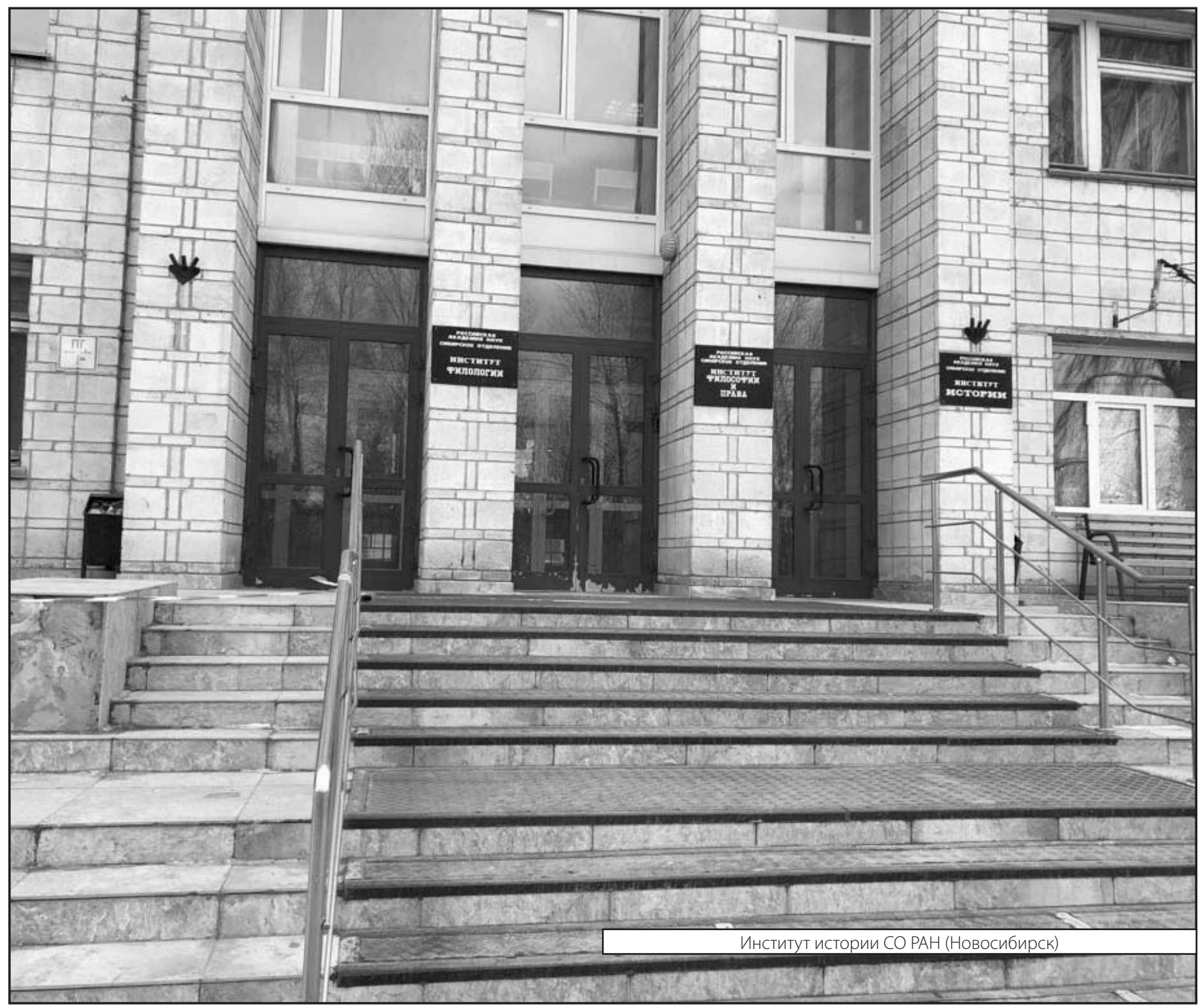

